\title{
S-Adenosylmethionine suppresses the expression of Smad3/4 in activated human hepatic stellate cells via Rac1 promoter methylation
}

\author{
KANGQI BIAN* ${ }^{*}$,FENG ZHANG ${ }^{*}$, TINGTING WANG, XIAOPING ZOU, XUHONG DUAN, \\ GUANGXIA CHEN and YUZHENG ZHUGE \\ Department of Gastroenterology, Affiliated Drum Tower Hospital of Nanjing University Medical School, \\ Nanjing, Jiangsu 210008, P.R. China
}

Received March 6, 2015; Accepted January 20, 2016

DOI: $10.3892 / \mathrm{mmr} .2016 .4997$

\begin{abstract}
The aim of the present study was to investigate whether S-adenosylmethionine (SAM) was able to suppress activated human hepatic stellate cells (HSCs). Human LX-2 HSCs were cultured with SAM or NSC23766, and were transfected with plasmids encoding ras-related $\mathrm{C} 3$ botulinum toxin substrate 1 (Rac1) protein or an empty expression vector. Cell proliferation was detected by Cell Counting Kit-8. Cell migration and invasion were determined using the Transwell assay. The expression levels of Rac1 and Smad3/4 were detected by reverse transcription-quantitative polymerase chain reaction (PCR) or western blotting. The methylation status of Rac1 promoters was measured by methylation-specific PCR. The results demonstrated that SAM and NSC23766 suppressed the expression of Smad3/4 in LX-2 cells. The overexpression of Racl enhanced the proliferation, migration and invasion of LX-2 cells. In addition, compared with the control groups, a marked increase was observed in the protein expression levels of Smad3/4 in the LX-2 cells transfected with Rac1 plasmids. The methylation-specific PCR findings showed that SAM increased the methylation of Rac1 promoters. The results of the present study suggested that Racl enhanced the expression of Smad3/4 in activated HSCs; however, this increase may be suppressed by SAM-induced methylation of Rac1 promoters.
\end{abstract}

Correspondence to: Professor Yuzheng Zhuge, Department of Gastroenterology, Affiliated Drum Tower Hospital of Nanjing University Medical School, 321 Zhongshan Road, Nanjing, Jiangsu 210008, P.R. China

E-mail: yuzheng9111963@aliyun.com

${ }^{*}$ Contributed equally

Key words: S-adenosylmethionine, hepatic fibrosis, hepatic stellate cells, ras-related $\mathrm{C} 3$ botulinum toxin substrate 1 , methylation

\section{Introduction}

Resident hepatic stellate cell (HSC) activation has been described as a central event in the development of hepatic fibrosis; therefore, activated HSCs are considered a major target for anti-fibrotic therapy (1). It has been reported that transforming growth factor- $\beta 1$ (TGF- $\beta 1$ )/Smad signaling is a pivotal pathway in hepatic fibrogenesis, and suppression of the TGF- $\beta 1 /$ Smad signaling pathway may inhibit collagen production and eventually alleviate hepatic fibrosis (2-5). Despite recent progress in hepatic fibrosis research, the mechanism underlying hepatic fibrogenesis remains to be fully elucidated, and certain issues in the approaches to anti-fibrotic treatment still need to be addressed.

The ras-related $\mathrm{C} 3$ botulinum toxin substrate 1 (Rac1) signaling pathway has been reported to regulate various biological processes, including cell proliferation, apoptosis, redox signaling, and gene transcription (6-8). Previous studies have shown that the overexpression of Racl is a novel pathway involved in hepatic fibrogenesis $(9,10)$. In keratinocytes, Rac1 has been reported to regulate TGF- $\beta 1$-mediated epithelial cell plasticity and matrix metalloproteinase (MMP)9 production (11). In addition, Rac1 may regulate the expression of Smad2/3 in pancreatic carcinoma cells; the suppression of Rac1 weakened the transcription and phosphorylation of Smad2 but enhanced the expression of Smad3 (12). Our previous study (13) indicated that $\mathrm{S}$-adenosylmethionine (SAM) reduces the expression of Rac1, Smad3 and Smad4 in activated HSCs; however, the association between Racl and Smads in activated HSCs has yet to be revealed.

In the present study, LX-2 cells, a cell line derived from activated human HSCs (14-18), were used to demonstrate that SAM suppresses the expression of Smad3/4 via methylating the Racl promoter in activated HSCs.

\section{Materials and methods}

Materials and chemicals. LX-2 cells were purchased from BioHermes Bio \& Medical Technology Co., Inc. (Meishan, China). Dulbecco's modified Eagle's medium (DMEM) was purchased from Wisent Inc. (Saint-Jean-Baptiste, QC, Canada). 
Fetal bovine serum (FBS) was obtained from Biological Industries (Beit Haemek, Israel), and SAM was from Abbott Laboratories (Lake Bluff, IL, USA). DC Protein Assay Reagent was supplied by Bio-Rad Laboratories, Inc., (Hercules, CA, USA). Cell Counting kit-8 (CCK-8) was purchased from Dōjindo Laboratories (Kumamoto, Japan), and Matrigel Basement Membrane Matrix and Cell Culture Inserts were obtained from BD Biosciences (San Jose, CA, USA). The QuantiTech Reverse Transcription and QuantiFast SYBR Green PCR kits for reverse transcription-quantitative polymerase chain reaction (RT-qPCR) were obtained from Qiagen (Hilden, Germany). The PrimeScript RT Master Mix for methylation-specific PCR (MSP) was purchased from Takara Bio, Inc., (Otsu, Japan). Transwell chambers were from EMD Millipore (Billerica, MA, USA). The primary monoclonal antibodies, mouse anti-human Rac1 (cat. no ab33186) and mouse anti-human Smad3/4 (cat. no. ab75512/ab130242), polyclonal rabbit anti-human $\beta$-actin (cat. no. ab8227), the polyclonal horseradish-peroxidase conjugated goat anti-mouse IgG (cat. no. ab6789) and goat anti-rabbit IgG (cat. no. ab6721) secondary antibodies were all purchased from Abcam (Cambridge, UK.)

Cell culture. LX-2 cells were maintained in DMEM (high glucose) medium supplemented with $10 \%$ FBS and $100 \mathrm{U} / \mathrm{ml}$ penicillin-streptomycin solution (Biological Industries) in an incubator containing $5 \% \mathrm{CO}_{2}$. Cells were divided into three treatment groups and incubated with $0 \mathrm{mM}, 4 \mathrm{mM}$ and $6 \mathrm{mM}$ of SAM for $24 \mathrm{~h}$.

Cell proliferation assay. LX-2 cells were recovered from the culture flask using $0.25 \%$ trypsin and $0.1 \%$ ethylenediaminetetraacetic acid, and were then seeded onto 96-well microplates at a density of $1 \times 10^{4}$ cells/well. The cell viability was evaluated with $\mathrm{CCK}-8$, according to the manufacturer's protocol, and was expressed as relative cell viability, using the following formula: Percentage of cell viability $(\%)=\mathrm{OD}$ of treated sample/OD of control sample) x $100 \%$. OD indicates optical density. The experiment was performed in triplicate.

Plasmid transfection. LX-2 cells were transfected with plasmids encoding Racl protein or an empty expression vector (Shanghai GeneChem Co., Ltd., Shanghai, China) using Lipofectamine ${ }^{\circledR} 2000$ (Invitrogen; Thermo Fisher Scientific, Inc., Waltham, MA, USA), according to the manufacturer's protocol. The Racl overexpression plasmid was fluorescently-labeled. The untransfected, vector-transfected and Rac1 plasmid-transfected cells were all harvested following incubation for $48 \mathrm{~h}$. Transfection efficiency was evaluated by RT-qPCR, western blotting and inverted fluorescent microscopy using an Axio Scope A1 microscope (Carl Zeiss AG, Oberkochen, Germany).

Transwell migration and invasion assays. Transwell migration and invasion assays were performed using the 8 -mm pore size Transwell system. For the cell invasion assay the chambers were coated with Matrigel, according to the manufacturer's protocol. Briefly, the chambers set on 24-well cluster plates were covered with $20 \mu \mathrm{l}$ Matrigel and were incubated for $30 \mathrm{~min}$ at $37^{\circ} \mathrm{C}$, whereas non-coated chambers were used for the cell migration assay. LX-2 cells post-transfection and control cells were resuspended in DMEM containing 0.5\% FBS, and were seeded at a density of $2 \times 10^{4}$ cells/well on the upper chamber of the Transwell. Complete medium $(0.5 \mathrm{ml})$ was added to the lower chamber. Following a $24 \mathrm{~h}$ incubation, the inner surface of the upper chamber was gently scrubbed using a cotton bud. The cells were fixed in methanol and stained with crystal violet. Cells that traversed the Transwell membrane were counted, and images corresponding to the entire membrane surface were captured using an Olympus inverted microscope equipped with a charge-coupled device camera (CKX41-F32FL; Olympus Corp., Tokyo, Japan). Five evenly spaced fields of cells were counted in each well. The assay was performed in triplicate. A group of cells was also treated with $50 \mu \mathrm{M}$ NSC23766 (Tocris Bioscience, Bristol, UK) for 48 h, a Rac1-specific inhibitor.

Western blot analysis. Proteins were extracted in lysis buffer [30 mM Tris, $\mathrm{pH}$ 7.5, $150 \mathrm{mM}$ sodium chloride, $1 \mathrm{mM}$ phenylmethylsulfonyl fluoride, $1 \mathrm{mM}$ sodium orthovanadate, $1 \%$ Nonidet P-40, 10\% glycerol, and phosphatase and protease inhibitor cocktail (Roche Diagnostics, GmbH, Mannheim, Germany)]. Total proteins $(30 \mu \mathrm{g})$ were then separated by $10 \%$ sodium dodecyl sulfate-polyacrylamide gel electrophoresis and electrophoretically transferred onto polyvinylidene fluoride membranes (0.45 $\mu \mathrm{l}$; EMD Millipore). They were quantified using a DC Protein Assay. The membranes were blocked with $5 \%$ non-fat milk and Tris-buffered saline with Tween 20 for 1 at room temperature. Next, they were probed with primary antibodies (Rac1, 1:1,000; Smad3, 1:5,000; Smad4, 1:1,000; $\beta$-actin, 1:1,000) overnight at $4^{\circ} \mathrm{C}$, and were then incubated with the secondary antibodies (goat anti-mouse $\operatorname{IgG}, 1: 2,000$; goat anti-rabbit IgG, 1:2,000) for $1 \mathrm{~h}$ at room temperature. The blots were visualized using Immobilon Western Chemiluminescent HRP Substrate (EMD Millipore). Images of the western blotting products were captured and analyzed using Quantity One V4.31 (Bio-Rad Laboratories, Inc.).

$R T-q P C R$. Total RNA was extracted from the cells with TRIzol (Invitrogen; Thermo Fisher Scientific, Inc.) and quantified using a spectrophotometer (NanoDrop 2000; Thermo Fisher Scientific, Inc.). The samples were treated with gDNA Wipeout Buffer from the QuantiFast SYBR kit. RT was performed with $1 \mu \mathrm{g}$ RNA in a total reaction volume of $20 \mu \mathrm{l}$ containing $200 \mathrm{U}$ Moloney murine leukemia virus reverse transcriptase, according to the manufacturer's protocol, using the following protocol: $42^{\circ} \mathrm{C}$ for $15 \mathrm{~min}$ and $95^{\circ} \mathrm{C}$ for $3 \mathrm{~min}$. The PCR primers $(\beta$-actin, forward 5'-AGCGAGCATCCCCCAAAGTT, reverse 5'-GGGCAC GAAGGCTCATCATT; Rac1, forward 5'-CCCTATCCTATC CGCAAACA, reverse 5'-CGCACCTCAGGATACCACTT; and $\alpha$-smooth muscle actin (SMA), forward 5'-ACTGGGACG ACGACATGGAAAAG and reverse 5'-TAGATGGGGACA TTGTGGGT) were designed and validated by Sangon Biotech Co., Ltd. (Shanghai, China). qPCR was performed at $95^{\circ} \mathrm{C}$ for $5 \mathrm{~min}$, followed by 40 cycles of amplification at $95^{\circ} \mathrm{C}$ for $10 \mathrm{sec}$ and $60^{\circ} \mathrm{C}$ for $30 \mathrm{sec}$ on an Applied Biosystems 7500 Real-Time PCR system (Applied Biosystems; Thermo Fisher Scientific, Inc.). The fluorescent signals were collected during the extension phase, quantification cycle $(\mathrm{Cq})$ values of the sample were calculated, and transcript levels were analyzed using the $2^{-\Delta \Delta \mathrm{Cq}}$ method (19). The results were normalized to $\beta$-actin and cDNA was prepared 30 times. 
$M S P$. Genomic DNA (gDNA; $1 \mu \mathrm{g}$ ) isolated from LX-2 cells was extracted when the cells were treated with lysis buffer and incubated with proteinase $\mathrm{K}$ for $10 \mathrm{~min}$, next cells were treated with bisulfite using the EZ DNA Methylation kit (Zymo Research Corp., Irvine, CA, USA), according to the manufacturer's protocol. The specific primers (methylated DNA: 164 bp PCR product, forward 5'-TTAATTAAAGTGTTGGGATGATAGAC, reverse 5'-AAATCTCTTAAACCTAAAAAACGAT; and unmethylated DNA: 164 bp PCR product, forward 5'-AATTAA AGTGTTGGGATGATAGATGT and reverse 5'-AAATCTCTT AAACCTAAAAAACAAT) were designed and synthesized by Sangon Biotech Co., Ltd. Normal lymphocytes collected from healthy human blood (Dr Xuejia Lu, Affiliated Drum Tower Hospital of Nanjing University Medical School, Nanjing, China) were used as the negative control, whereas normal lymphocytes treated with bisulfite-converted gDNA were used as the positive control. The modified DNA was immediately used for MSP. The PCR was carried out using PrimeScript RT Master Mix (Takara Bio, Inc.) under the following conditions: $98^{\circ} \mathrm{C}$ for $10 \mathrm{~min}, 53^{\circ} \mathrm{C}$ for $30 \mathrm{~min}, 8$ cycles of $53^{\circ} \mathrm{C}$ for $6 \mathrm{~min}$ and $37^{\circ} \mathrm{C}$ for $30 \mathrm{~min}$. The methylated and unmethylated DNA was distinguished after running on a $3 \%$ agarose gel and was stained with GelRed DNA-binding dye (Biotium, Inc., Hayward, CA, USA).

Immunofluorescence (IF). LX-2 cells were seeded onto 24-well plates containing a sterile glass slide at a density of $2 \times 10^{4}$ cells/well. Following incubation in high-glucose DMEM medium supplemented with $10 \% \mathrm{FBS}$ and antibiotics at $37^{\circ} \mathrm{C}$ in a humidified incubator containing $5 \% \mathrm{CO}_{2}$ for $24 \mathrm{~h}$, the cells coated on the glass slide were washed three times with cold phosphate-buffered saline (PBS) and fixed with $4 \%$ paraformaldehyde for $20 \mathrm{~min}$ at room temperature. Following blocking with $1 \%$ non-fat milk for $2 \mathrm{~h}$, the cells were incubated with primary antibodies (Smad3 and Smad4) at a dilution of 1:250 overnight at $4^{\circ} \mathrm{C}$. Subsequently, the slides were washed three times with $0.5 \%$ PBS-Tween 20 and incubated with fluorescein isothiocyanate-conjugated goat anti-mouse IgG H\&L Alexa Fluor 488 secondary antibody (cat. no. ab150117; Abcam) at a dilution of $1: 1,000$ at $37^{\circ} \mathrm{C}$ for $2 \mathrm{~h}$. Eventually, the slides were washed and examined using the inverted fluorescence microscope. Five random high power field images were taken in each group.

Statistical analysis. Statistical analysis was performed using SPSS 13.0 (SPSS Inc., Chicago, IL, USA). Results are presented as the mean \pm standard deviation of at least three independent experiments. The significant differences among the groups were evaluated by a Student's t-test. $\mathrm{P}<0.05$ was considered to indicate a statistically significant difference.

\section{Results}

SAM suppresses the expression of Smad3/4 in LX-2 cells. To determine the mechanism underlying SAM-induced reversal of LX-2 HSC activation, the protein expression levels of Smad3/4 were examined in cells treated with various concentrations of SAM for $24 \mathrm{~h}$. As shown in Fig. 1, the protein expression of Smad3 and Smad4 in the SAM-treated groups (4 and $6 \mathrm{mM}$ SAM) was significantly decreased compared with in the control group $(\mathrm{P}<0.05)$, as determined by western blotting. This result
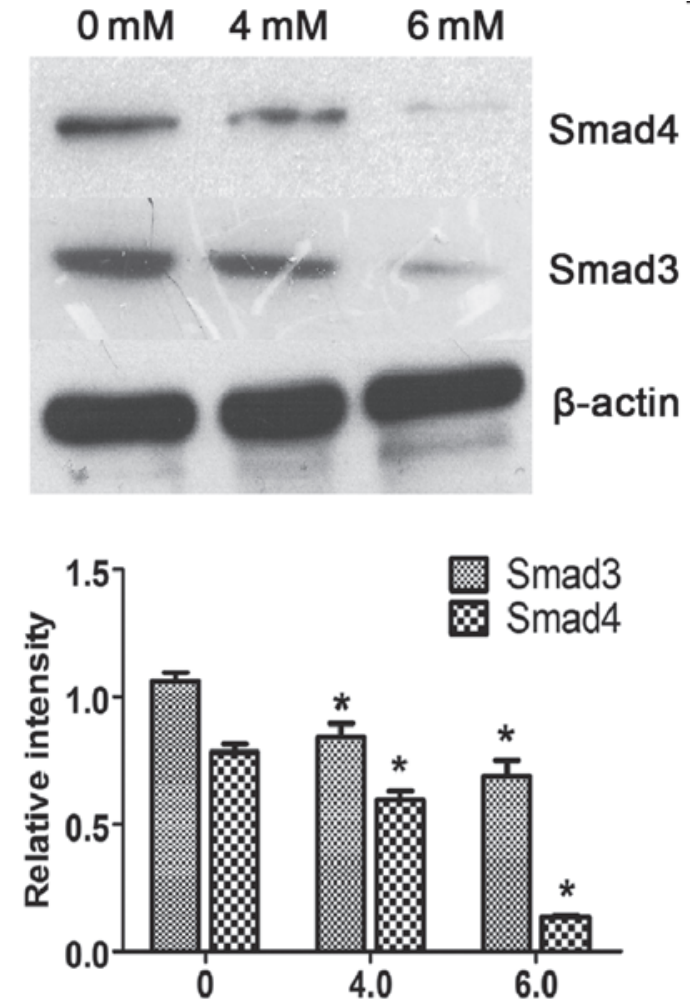

Figure 1. SAM suppresses the expression of Smad3/4 in LX-2 cells. Western blotting showed that the total protein of Smad3/4 in the 4 and $6 \mathrm{mM} \mathrm{SAM}$ groups was significantly decreased compared with that in the control group. Data are presented as the mean \pm standard deviation. ${ }^{*} \mathrm{P}<0.05$, compared with the control group. SAM, S-adenosylmethionine.

indicates an inhibitory effect of SAM on the expression of Smad3/4

Racl enhances the proliferation, migration and invasion of $L X-2$ cells. Following transfection of the cells with plasmids encoding Racl protein or an empty expression vector for $48 \mathrm{~h}$, the expression of Racl in the LX-2 cells was examined. The mRNA expression levels of Racl in the Racl plasmid-transfected cells were significantly increased compared with in the vector-transfected cells, as determined by RT-qPCR ( $<<0.05$; Fig. 2A). Similarly, the protein expression levels of Racl were also increased in response to Racl plasmid transfection (Fig. 2B), confirming that the transfection was successful.

To investigate the role of Racl in the proliferation of LX-2 cells, CCK- 8 assay was performed. The results showed that the overexpression of Rac1 significantly facilitated the proliferation of LX-2 cells compared with the vector-transfected cells $(\mathrm{P}<0.05)$; however, proliferation was reduced when the activity of Rac1 was suppressed by a specific inhibitor, NSC23766 (Fig. 2C).

Transwell assay was performed in order to determine the effects of Racl on the migration and invasion of the transfected LX-2 cells. The results indicated that the number of migrated or invaded cells was significantly increased in the Rac1 plasmid-transfected group compared with in the vector-transfected group $(\mathrm{P}<0.05$; Fig. 2D and $\mathrm{E})$.

Racl promotes the expression of Smad3/4 in LX-2 cells. Compared with the vector-transfected cells, Rac1 
A

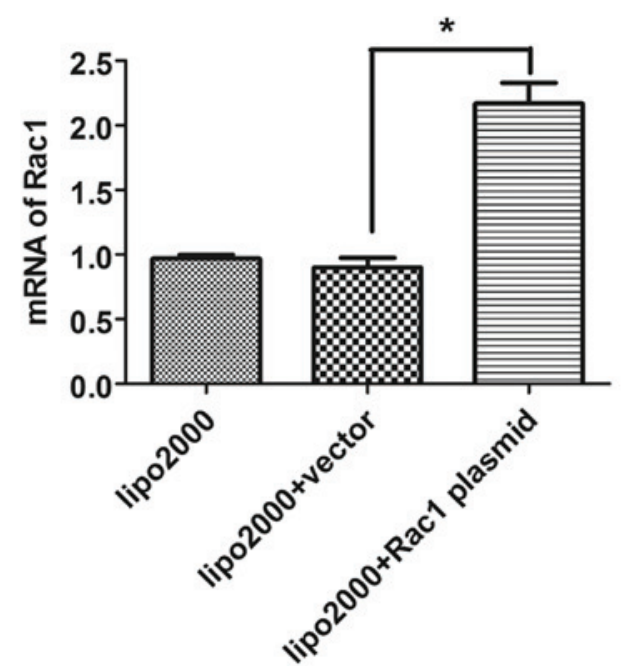

C

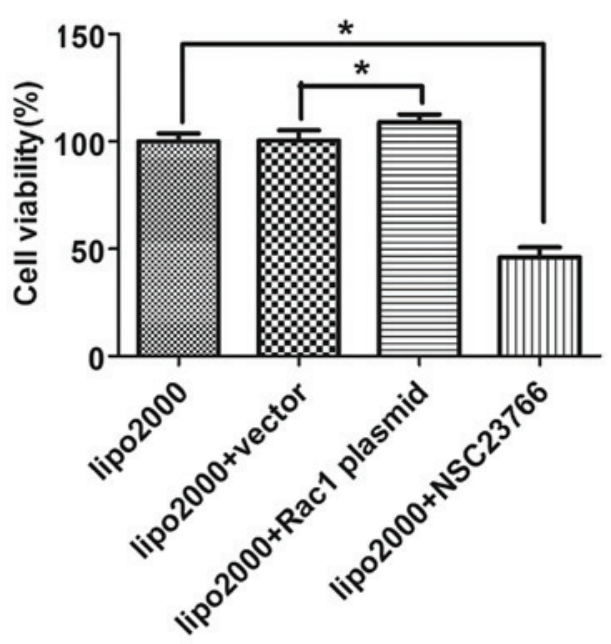

B

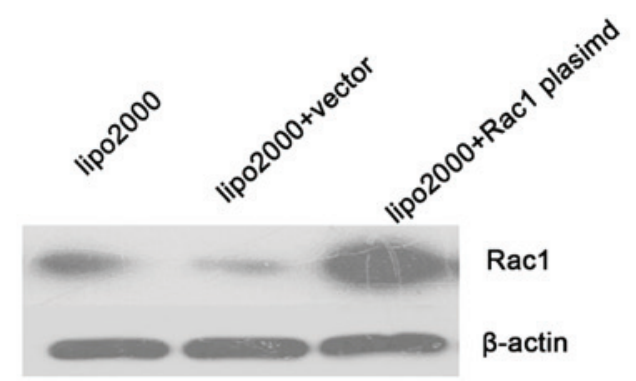

D
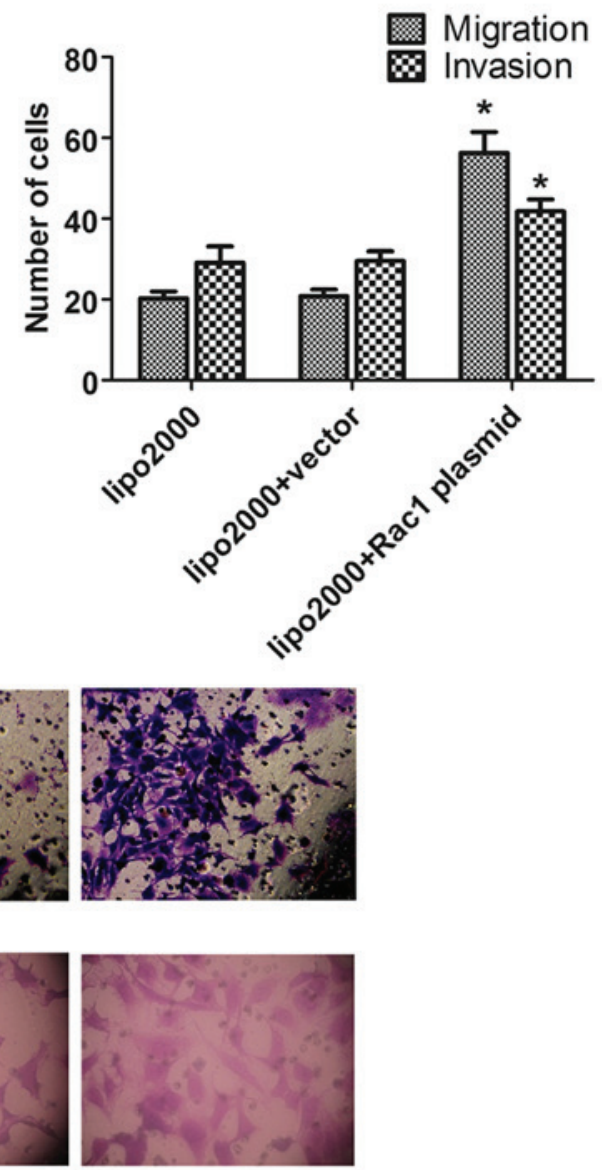

lipo2000+Rac1

Plasmid

Figure 2. Rac1 enhances the proliferation, migration and invasion of LX-2 cells. (A and B) Reverse transcription-quantitative polymerase chain reaction and western blotting showed that the expression of Rac1 in Rac1 plasmid-transfected LX-2 cells was significantly increased compared with that in the vector-transfected cells. (C) Rac1 overexpression enhanced the proliferation of LX-2 cells, as determined by Cell Counting Kit-8, whereas the NSC23766-induced inhibition of Rac1 activity suppressed cell proliferation. (D and E) Rac1 overexpression in LX-2 cells enhanced the migration and invasion of LX-2 cells. Magnification, $\mathrm{x} 400$. Data are presented as the mean \pm standard deviation. ${ }^{*} \mathrm{P}<0.05$ vs vector group. Rac1, ras-related $\mathrm{C} 3$ botulinum toxin substrate $1 ;$ lipo2000, Lipofectamine ${ }^{\circledR} 2000$.

plasmid-transfected LX-2 cells exhibited a marked increase in Smad3/4 protein expression (Fig. 3A and B). Smad3/4 expression detected by IF was consistent with the results of the western blot analysis (Fig. 3C). These findings indicate that Rac1 may act as part of an upstream signaling pathway that promotes the expression of Smad3/4 in LX-2 cells. In addition, the expression levels of $\alpha$-SMA were detected by RT-qPCR. The mRNA expression levels of $\alpha$-SMA were significantly increased in the Racl plasmid-transfected cells compared with in the vector-transfected cells (Fig. 3D), thus 


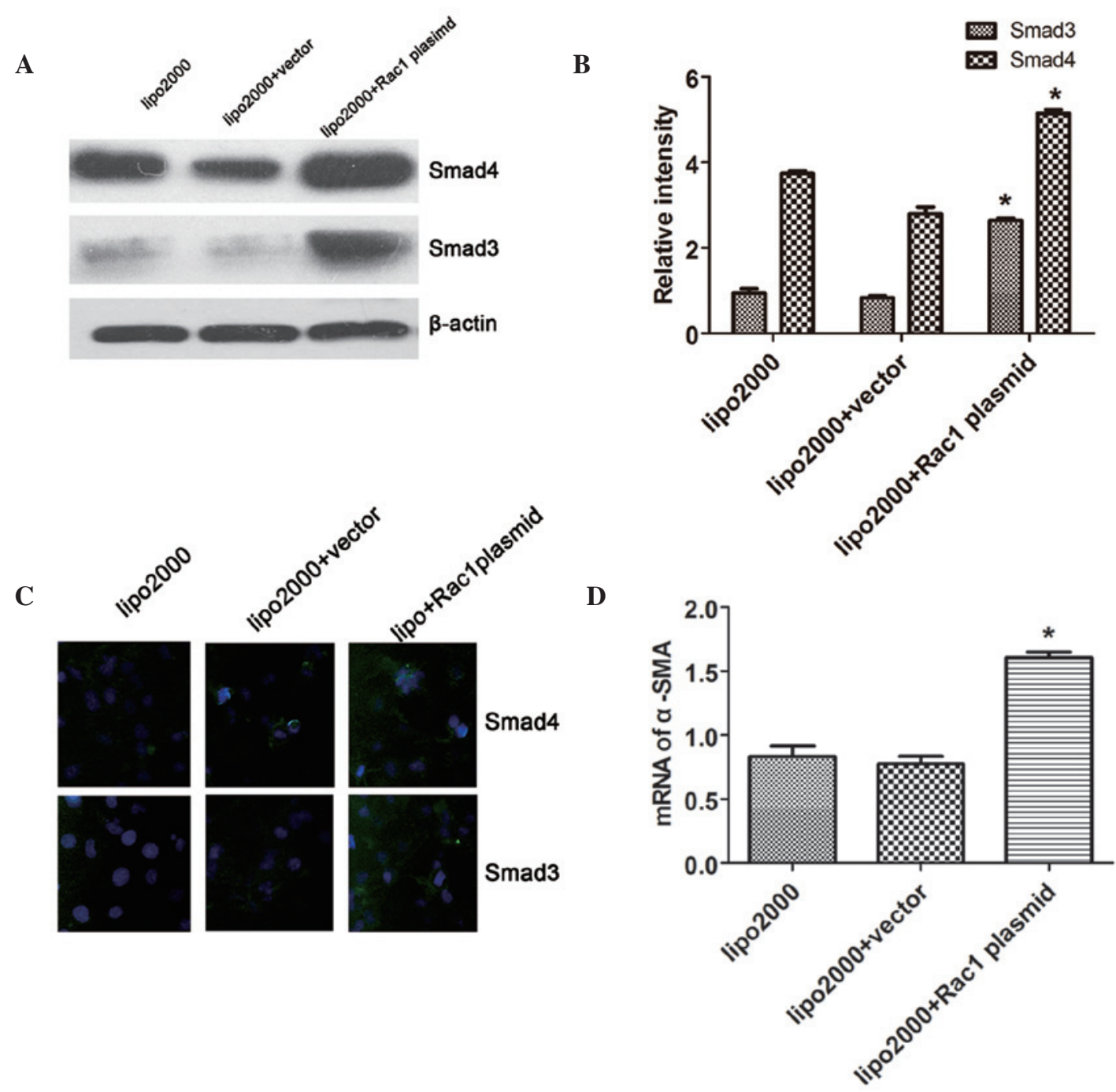

Figure 3. Rac1 upregulates the expression of Smad3/4 in LX-2 cells. (A and B) Western blotting indicated that the total protein of Smad3/4 in Rac1 plasmid-transfected cells was significantly increased compared with in the vector-transfected cells. (C) Smad3/4 expression was measured by immunofluorescence, and the results were consistent with those of western blotting. (D) Reverse transcription-quantitative polymerase chain reaction showed that the mRNA expression of $\alpha$-SMA was upregulated by Rac1. Magnification, $\mathrm{x} 400$. Data are presented as the mean \pm standard deviation. ${ }^{*} \mathrm{P}<0.05$, compared with the vector-transfected group. Rac1, ras-related C3 botulinum toxin substrate 1; $\alpha$-SMA, $\alpha$-smooth muscle actin; lipo2000, Lipofectamine ${ }^{\circledR} 2000$.

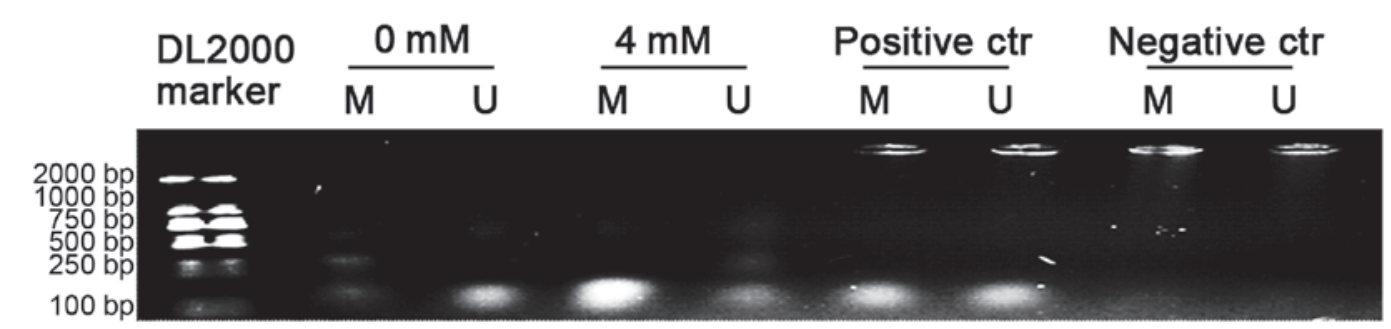

Figure 4. Rac1 promoter is methylated by SAM in LX-2 cells. Normal lymphocytes collected from healthy human blood were used as the negative control, whereas normal lymphocytes treated with bisulfite-converted genomic DNA were used as the positive control. Racl promoter was significantly methylated in the $4 \mathrm{mM}$ SAM-treated group compared with in the untreated group. The polymerase chain reaction product of the Racl promoter was $164 \mathrm{bp}$. M, methylated; U, unmethylated; ctr, control; Rac1, ras-related C3 botulinum toxin substrate 1; SAM, S-adenosylmethionine.

indicating that the overexpression of Rac1 facilitates the activation of HSCs.

SAM increases methylation of the Racl promoter. gDNA was extracted from LX-2 cells treated with $4 \mathrm{mM}$ SAM for $24 \mathrm{~h}$, and from untreated control cells for MSP. As shown in Fig. 4, a strong signal was observed in the bisulite-converted lymphocyte DNA (positive control) amplified with both methylated and unmethylated allele-specific MSP primers, which were not effective at amplifying the negative control. A markedly increased methylation status was shown in the SAM-treated cells compared with the untreated ones, which indicated that 
the Rac1 promoter could be methylated by SAM in LX-2 cells, explaining the inhibitory effect of SAM on Racl expression.

\section{Discussion}

Rac1, which is a member of the Rho family of GTPases, is an important intracellular transducer. Rac1 is known to induce cytoskeletal rearrangement, and is required for cell migration, proliferation and gene transcription. Previous studies have reported that Rac1 regulates the TGF- $\beta 1 /$ Smad signaling pathway $(11,20)$. In addition, Rac1 may regulate the expression of $S m a d 2 / 3$ in pancreatic carcinoma cells, facilitating cell proliferation and mobility, whereas the suppression of Rac1 weakens the transcription and phosphorylation of Smad2 but enhances that of Smad3 (12). In keratinocytes, Rac1 has been reported to regulate TGF- $\beta 1$-mediated epithelial cell plasticity and MMP9 production (11); however, the interaction between Rac1 and Smad4 has not yet been detected. Racl has also been shown to facilitate the synthesis of collagen, as mediated by TGF- $\beta 1$ (21). Our previous study (13) demonstrated that SAM inhibited the activated phenotype of HSCs, probably via Rac1, and that SAM attenuated the expression of Smad3/4; however, the association between Racl and Smads in activated HSCs is currently unknown.

The present study focused on the regulating effect of Rac1 on the expression of Smad3/4 in activated HSCs, and on further demonstrating the anti-fibrotic mechanism of SAM. To validate the effects of Rac1, plasmids encoding Racl protein or an empty expression vector were transfected into LX-2 cells. The results demonstrated that the expression levels of $\operatorname{Smad} 3$ and Smad4 were markedly increased by overexpression of Rac1, which had not previously been demonstrated. Conversely, the expression levels of Smad3 and Smad4 were decreased when the expression of Rac1 was downregulated by NSC23766. Furthermore, following our previous study, the mechanism underlying the inhibitory effects of SAM on Rac1 expression was explored. SAM, which is an intermediate product of L-methionine metabolism, is a precursor of glutathione and an endogenous methyl donor. SAM regulates the expression of target genes through altering the methylation status; therefore, the present study examined the methylation status of the Rac1 promoter. The results indicated that the Rac1 promoter was highly methylated by SAM.

Smad2/3 form a hetero-oligomeric complex with Smad4, which translocates into the nucleus of HSCs where it induces target gene transcription and mediates hepatic fibrosis (1). It has previously been reported that partly suppressing the TGF- $\beta 1 /$ Smad signaling pathway could delay or reverse hepatic fibrosis $(22,23)$; however, a complete block of the TGF- $\beta 1 /$ Smad pathway also increases the risk of tumorigenesis. Therefore, targeting selected Smads in TGF- $\beta 1 / \mathrm{Smad}$ could comprise a potential treatment for fibrosis (24).

The present study demonstrated that Rac1 may have a promising role in the regulation of $\mathrm{Smad} 3 / 4$ expression, thus revealing a novel mechanism for the reversal of liver fibrosis. The present findings suggested that the expression of $\operatorname{Smad} 3 / 4$ in activated HSCs could be enhanced by the overexpression of Rac1, whereas SAM suppressed the expression of Smad3/4, probably via methylation of the Rac1 promoter, which would result in subsequent downregulation. The present study provided a molecular basis for a potential application of SAM and Rac1 in the treatment of hepatic fibrosis.

\section{Acknowledgements}

The present study was supported by the Natural Science Foundation of Jiangsu Province (grant no. BK2011094) and the Fundamental Research Funds for the Central Universities (grant no. 20620140710).

\section{References}

1. Lee UE and Friedman SL: Mechanisms of hepatic fibrogenesis. Best Pract Res Clin Gastroenterol 25: 195-206, 2011.

2. Bian EB, Huang C, Wang H, Chen XX, Zhang L, Lv XW and Li J: Repression of Smad7 mediated by DNMT1 determines hepatic stellate cell activation and liver fibrosis in rats. Toxicol Lett 224: 175-185, 2014.

3. He Y, Huang C, Sun X, Long XR, Lv XW and Li J: MicroRNA-146a modulates TGF-beta1-induced hepatic stellate cell proliferation by targeting SMAD4. Cell Signal 24: 1923-1930, 2012.

4. Liu Y, Wang Z, Wang J, Lam W, Kwong S, Li F, Friedman SL, Zhou S, Ren Q, Xu Z, et al: A histone deacetylase inhibitor, largazole, decreases liver fibrosis and angiogenesis by inhibiting transforming growth factor- $\beta$ and vascular endothelial growth factor signalling. Liver Int 33: 504-515, 2013.

5. Szuster-Ciesielska A, Mizerska-Dudka M, Daniluk J and Kandefer-Szerszeń M: Butein inhibits ethanol-induced activation of liver stellate cells through TGF- $\beta, \mathrm{NF} \kappa \mathrm{B}, \mathrm{p} 38$, and JNK signaling pathways and inhibition of oxidative stress. J Gastroenterol 48: 222-237, 2013.

6. Bosco EE, Mulloy JC and Zheng Y: Rac1 GTPase: A "Rac" of all trades. Cell Mol Life Sci 66: 370-374, 2009.

7. Nagase M andFujitaT:Role of Rac1-mineralocorticoid-receptor signalling in renal and cardiac disease. Nat Rev Nephrol 9: 86-98, 2013

8. Elnakish MT, Hassanain HH, Janssen PM, Angelos MG and Khan M: Emerging role of oxidative stress in metabolic syndrome and cardiovascular diseases: Important role of Rac/NADPH oxidase. J Pathol 231: 290-300, 2013.

9. Muhanna N, Doron S, Wald O, Horani A, Eid A, Pappo O, Friedman SL and Safadi R: Activation of hepatic stellate cells after phagocytosis of lymphocytes: A novel pathway of fibrogenesis. Hepatology 48: 963-977, 2008.

10. Bopp A, Wartlick F, Henninger C, Kaina B and Fritz G: Rac1 modulates acute and subacute genotoxin-induced hepatic stress responses, fibrosis and liver aging. Cell Death Dis 4: e558, 2013

11. Santibáñez JF, Kocić J, Fabra A, Cano A and Quintanilla M: Rac1 modulates TGF-beta1-mediated epithelial cell plasticity and MMP9 production in transformed keratinocytes. FEBS Lett 584: 2305-2310, 2010.

12. Ungefroren H, Groth S, Sebens S, Lehnert H, Gieseler F and Fändrich F: Differential roles of Smad2 and Smad3 in the regulation of TGF- $\beta 1$-mediated growth inhibition and cell migration in pancreatic ductal adenocarcinoma cells: Control by Rac1. Mol Cancer 10: 67, 2011.

13. Zhang F, Zhuge YZ, Li YJ and Gu JX: S-adenosylmethionine inhibits the activated phenotype of human hepatic stellate cells via Rac1 and matrix metalloproteinases. Int Immunopharmacol 19: 193-200, 2014.

14. Yang C,Zeisberg M, Mosterman B, Sudhakar A, Yerramalla U, Holthaus K, Xu L, Eng F, Afdhal N and Kalluri R: Liver fibrosis: Insights into migration of hepatic stellate cells in response to extracellular matrix and growth factors. Gastroenterology 124: 147-159, 2003.

15. Xu L, Hui AY, Albanis E, Arthur MJ, O'Byrne SM, Blaner WS, Mukherjee P, Friedman SL and Eng FJ: Human hepatic stellate cell lines, LX-1 and LX-2: New tools for analysis of hepatic fibrosis. Gut 54: 142-151, 2005.

16. Hendrickson H, Chatterjee S, Cao S, Morales Ruiz M, Sessa WC and Shah V: Influence of caveolin on constitutively activated recombinant eNOS: Insights into eNOS dysfunction in BDL rat liver. Am J Physiol Gastrointest Liver Physiol 285: G652-G660, 2003. 
17. Werneburg NW, Yoon JH, Higuchi H and Gores GJ: Bile acids activate EGF receptor via a TGF-alpha-dependent mechanism in human cholangiocyte cell lines. Am J Physiol Gastrointest Liver Physiol 285: G31-G36, 2003.

18. Taimr P, Higuchi H, Kocova E, Rippe RA, Friedman S and Gores GJ: Activated stellate cells express the TRAIL receptor-2/death receptor-5 and undergo TRAIL-mediated apoptosis. Hepatology 37: 87-95, 2003.

19. Livak KJ and Schmittgen TD: Analysis of relative gene expression data using real-time quantitative PCR and the 2(-Delta Delta C(T)) Method. Methods 25: 402-408, 2001.

20. Bakin AV, Rinehart C, Tomlinson AK and Arteaga CL: p38 mitogen-activated protein kinase is required for TGFbeta-mediated fibroblastic transdifferentiation and cell migration. J Cell Sci 115: 3193-3206, 2002.
21. Hubchak SC, Sparks EE, Hayashida T and Schnaper HW: Rac1 promotes TGF-beta-stimulated mesangial cell type I collagen expression through a PI3K/Akt-dependent mechanism. Am J Physiol Renal Physiol 297: F1316-F1323, 2009.

22. Tang LX, He RH, Yang G, Tan JJ, Zhou L, Meng XM, Huang XR and Lan HY: Asiatic acid inhibits liver fibrosis by blocking TGF-beta/Smad signaling in vivo and in vitro. PLoS One 7: e31350, 2012

23. Karaa A, Thompson KJ, McKillop IH, Clemens MG and Schrum LW: S-adenosyl-L-methionine attenuates oxidative stress and hepatic stellate cell activation in an ethanol-LPS-induced fibrotic rat model. Shock 30: 197-205, 2008.

24. Inagaki Y and Okazaki I: Emerging insights into Transforming growth factor beta Smad signal in hepatic fibrogenesis. Gut 56: 284-292, 2007. 